\title{
Entry of Xanthomonas campestris pv. campestris into Hydathodes of Arabidopsis thaliana Leaves: A System for Studying Early Infection Events in Bacterial Pathogenesis
}

\author{
Véronique Hugouvieux, Christine E. Barber, and Michael J. Daniels \\ The Sainsbury Laboratory, John Innes Centre, Norwich Research Park, Norwich NR4 7UH, UK \\ Accepted 26 February 1998.
}

\begin{abstract}
Xanthomonas campestris pv. campestris (Xcc) is a vascular pathogen of cruciferous plants that normally gains entry to plants via hydathodes. In order to study the basis of the preference for this portal of entry we have developed an Arabidopsis thaliana model with attached or detached leaves partially immersed in a bacterial suspension. Entry of bacteria into leaves, assessed by resistance to surface sterilization, could be detected after $1 \mathrm{~h}$. Dissection of leaves and histochemical staining for $\beta$-glucuronidase produced by the bacteria indicated that they were located in hydathodes. In contrast, similar experiments with the leaf-spotting pathogen $X$. campestris pv. armoraciae gave patterns of localized staining dispersed over the leaf area, indicative of entry through stomata. A survey of $41 A$. thaliana accessions showed that they fell into three classes distinguishable by total numbers of $X c c$ that entered under standard conditions and by preference for hydathode colonization. Previously isolated Xcc mutants affected in pathogenicity were tested for hydathode colonization: an hrp mutant behaved indistinguishably from the wild type, and $r p f$ regulatory mutants gave $\mathbf{1 0}$-fold reduced colonization, whereas with $r f a X$ mutants with altered lipopolysaccharide, few if any viable bacteria were recoverable from hydathodes. This fact, together with the rapid induction of superoxide dismutase in the bacteria located in hydathodes, suggests that an early defense reaction is mounted in the hydathode.
\end{abstract}

Additional keywords: black rot, crucifer.

Although substantial progress has been made in understanding the mechanisms of bacterial pathogenesis and of plant resistance and response to pathogens, many aspects of the plant-bacterial interaction remain relatively unexplored. In particular, little is known about the factors that permit or promote entry of most bacterial pathogens from the external environment (phylloplane, rhizoplane, etc.) into plant tissues to initiate infection. The paucity of published information may

Corresponding author: Michael J. Daniels, The Sainsbury Laboratory, John Innes Centre, Norwich Research Park, Norwich NR4 7UH, UK: Telephone: (44) 1603 452571; Fax: (44) 1603 250024; E-mail: mike.daniels@bbsrc.ac.uk be a consequence of the general perception that bacteria, in contrast to many fungi, do not possess active mechanisms for penetrating intact plant surfaces and gaining entry into plants. Most bacteria that infect aerial portions of plants gain access through wounds or natural openings such as stomata. However, Xanthomonas campestris pv. campestris (Xcc), the agent of black rot of crucifers (Onsando 1992), invades primarily through hydathodes, structures containing water pores located at leaf margins (Smith 1897; Cook et al. 1952). Under suitable weather conditions, commonly encountered early in the morning, the hydathodes exude copious quantities of fluid, which collects around leaf margins as guttation drops. These drops become contaminated with epiphytic bacteria. Later, the guttation fluid may be drawn back into the leaf, carrying the suspended bacteria into the hydathode cavity and thence into the vascular system. $X c c$ is found primarily in the xylem of infected plants (Bretschneider et al. 1989), and bacterial progression along the xylem is followed by the typical symptoms of vein blackening and V-shaped chlorotic and necrotic lesions extending from leaf margins along veins (Sutton and Williams 1970; Wallis et al. 1973). Hydathode entry appears to be characteristic of $X c c$; other closely related, crucifer-infecting pathovars such as $X$. campestris pv. armoraciae enter leaves via wounds or stomata and cause leaf spot symptoms (Black and Machmud 1983; Hunter et al. 1987). This raises the possibility that the preference of $X c c$ for hydathode entry reflects the existence of specific mechanisms for this purpose. Since most molecular genetic studies of pathogenicity of Xcc have used inoculation methods that bypass the hydathode, by introducing bacteria into wounds or by infiltrating suspensions through stomata into leaf spaces, it is possible that any genes that determine "portal of entry specificity" have escaped discovery. From comparison of the effects of inoculation of Xcc by spraying bacterial suspensions onto intact leaves or by injection directly into veins, it has been inferred that the properties of the hydathode may also be important for determining resistance of some brassicas to Xcc (Staub and Williams 1972; Shaw and Kado 1988).

These several considerations have led us to investigate the early steps of entry of Xcc into plants. In this paper we describe an experimental system that is suitable for genetic studies of both the bacteria and the host plant. We have used Arabidopsis thaliana, which has been shown to be a conven- 
ient experimental host for Xcc (Simpson and Johnson 1990; Tsuji et al. 1991; Parker et al. 1993). Lummerzheim et al. (1993) inoculated A. thaliana plants by spraying bacterial suspensions onto leaves. Although this method probably results in hydathode infection, it gave inconsistent results in our hands and was inconvenient for large-scale screens. Our procedure uses either attached or detached leaves, and is suitable for miniaturized screening. Most importantly, the preference of Xcc for hydathode entry and of X. campestris pv. armoraciae for stomatal entry is exhibited in our system. We describe the characteristics of the method and illustrate its application to the study of bacterial mutants and plant variation. Our studies also suggest the existence of hydathode-based defense reactions.

\section{RESULTS}

\section{Development of the hydathode infection procedure.}

We reasoned that entry of bacteria into hydathodes or other plant compartments would render them insensitive to surface sterilization agents that do not penetrate the plant cuticle. The procedure described in Materials and Methods was developed empirically. The initial criteria used were that (i) immediately after application of bacteria to the leaf surface, by dipping leaves into a bacterial suspension, all the bacteria should be external and should be killed by the sterilization, and (ii) with time, an increasing number of bacteria would become refractory to killing because they had entered hydathodes and thus occupied a protected internal environment. Brief treatment with sodium hydrochlorite/Tween 80 solution followed by washing with sterile water, as described below, consistently fulfilled these requirements. A range of other sterilizing agents tested at various concentrations and exposure times, including ethanol, isopropanol, and hydrogen peroxide, gave inconsistent and unsatisfactory results.

Figure 1 shows the two methods used to apply bacteria to surfaces of attached or detached leaves, described in Materials and Methods. The leaves were removed from the bacterial suspensions after the desired time and processed further. The number of leaf-associated bacteria resistant to surface sterilization began to increase shortly after dipping the leaves. An initial plateau value was reached after 2 to $4 \mathrm{~h}$ of, typically, 2,000 to 5,000 bacteria per leaf under the standard conditions. Thereafter, the number continued to increase (Fig. 2). Within experiments, the behavior of individual replicate leaves was reproducible; an experiment in which 12 leaves were processed separately yielded a coefficient of variation of bacterial numbers of 0.096. Therefore, it was considered satisfactory in most experiments to pool replicate leaves for determination of mean bacterial numbers. Unless otherwise specified, leaves were exposed to bacterial suspensions for $2 \mathrm{~h}$. The behavior was similar for both detached and attached leaves. Some plants, attached leaves of which had been dipped in Xcc suspensions for $2 \mathrm{~h}$ before washing, were returned to a growth cabinet maintained at $22^{\circ} \mathrm{C}$. Symptoms typical of those produced by Xcc (Simpson and Johnson 1990; Parker et al. 1993) developed on the treated leaves after 7 to 10 days.

\section{Location of the protected bacteria.}

After exposure of leaves to $X c c$ and surface sterilization, leaves were fractionated into peripheral strips (which contained hydathode regions), and the remaining bulk tissue and the samples were separately homogenized. The bacterial contents were determined; $95 \%$ of the bacteria were typically as-

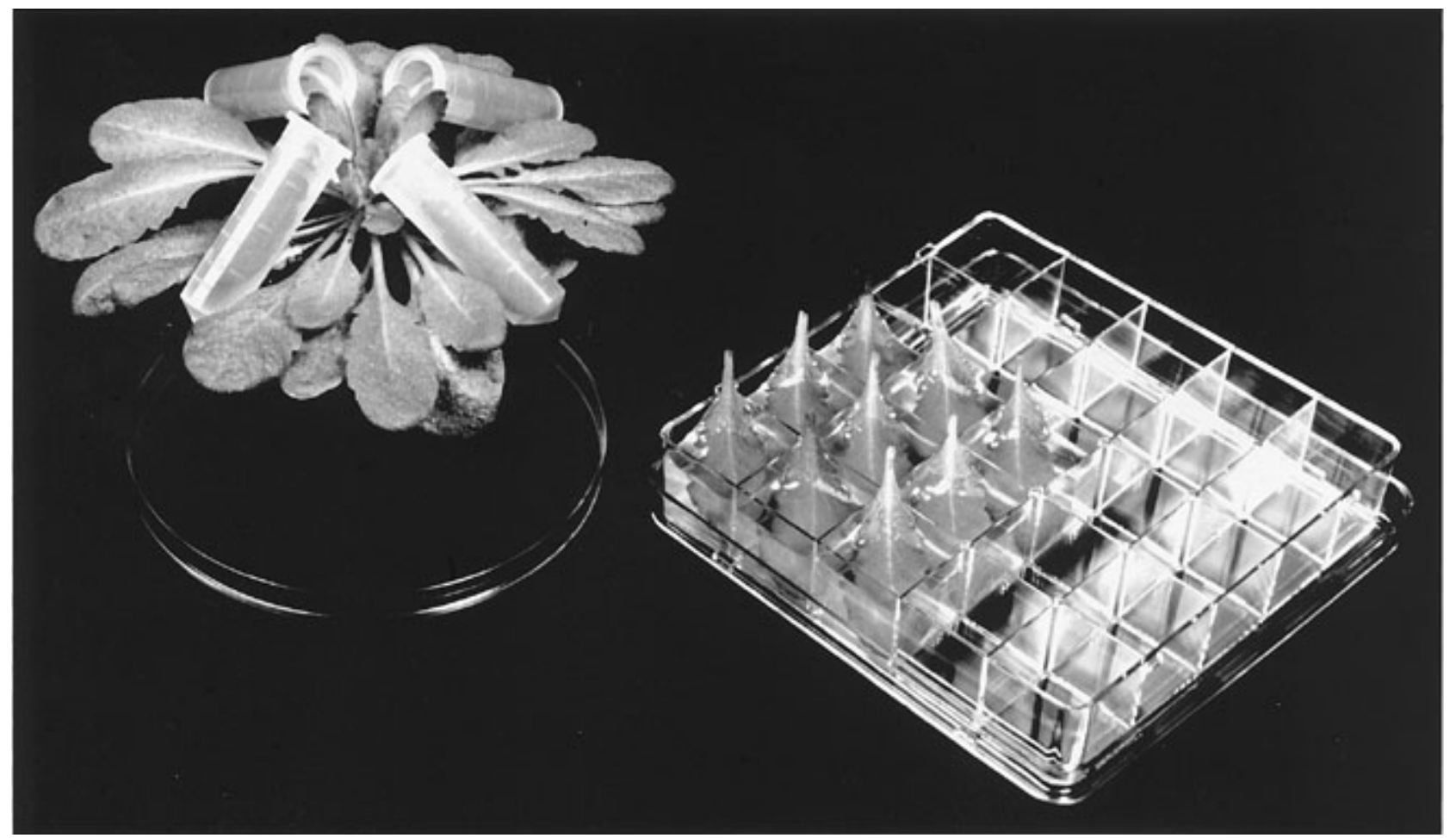

Fig. 1. Illustration of the procedures used for hydathode inoculation of Arabidopsis thaliana with Xanthomonas campestris pv. campestris, with attached leaves (left) inserted into open tubes containing the bacterial suspension, and detached leaves (right) dipped into suspensions in "Replidishes." 
sociated with the margins. In a second series of experiments, bacteria carrying a plasmid, pL3GUS-A, with a constitutively expressed $\beta$-glucuronidase (GUS) transcriptional fusion reporter gene were used. After immersion in bacterial suspensions, surface-sterilization, and incubation for 4 to $6 \mathrm{~h}$ to allow expression of the GUS gene, histochemical detection of the (intracellular) enzyme showed that $X c c$ was confined to the hydathode regions of the leaves (Fig. 3A). However, when a similar experiment was carried out with $X$. campestris pv. armoraciae, a leaf spot pathogen that enters via stomata, the staining was observed in patches over the leaf surface (Fig. 3B).

\section{Factors that influence entry of $X c c$ into leaves.}

Above $10^{7} \mathrm{CFU} \cdot \mathrm{ml}^{-1}$ the concentration of bacteria in the suspension used for leaf dipping had little significant effect on the number entering hydathodes, but more dilute suspensions gave substantially lower numbers. The standard conditions $\left(10^{8} \mathrm{CFU} \cdot \mathrm{ml}^{-1}\right)$ gave consistent results.

Bacteria were harvested from liquid batch cultures at different points throughout the growth cycle, suspended at a density of $10^{8} \mathrm{CFU} \cdot \mathrm{ml}^{-1}$, and tested with detached leaves. Bacteria from early stationary phase entered leaves in greatest numbers. The optical density (OD; $600 \mathrm{~nm}$ ) at which the bacteria were harvested and the relative number of bacteria in leaves were as follows: $0.25,0 \% ; 0.42,5 \% ; 0.87,27 \% ; 1.2,100 \%$; and $1.4,26 \%$. The last OD value corresponds to the maximum bacterial density attained in stationary phase cultures after 30 $\mathrm{h}$ under standard culture conditions. Leaves of various ages from rosettes were tested. There was little effect of age on bacterial entry. For convenience in handling, leaves 1.5 to 2.5 $\mathrm{cm}$ long were routinely used. Incubation temperatures of 22 to $25^{\circ} \mathrm{C}$ were optimal for immersion of detached leaves. A lower temperature $\left(15^{\circ} \mathrm{C}\right)$ resulted in fewer bacteria entering,

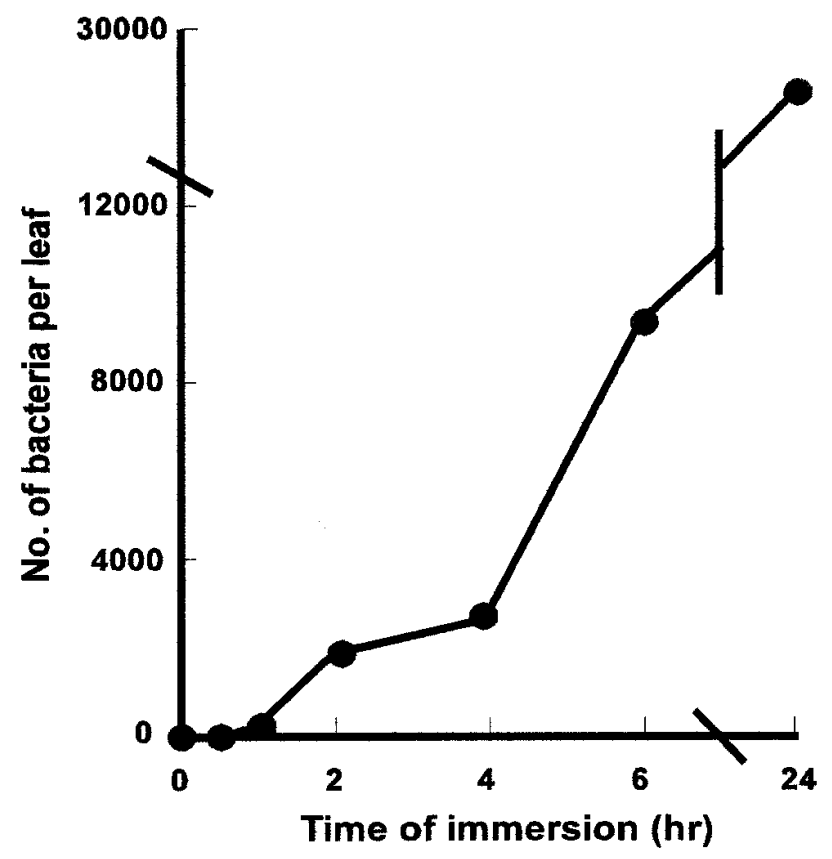

Fig. 2. Kinetics of entry of Xanthomonas campestris pv. campestris into detached leaves (cf. Figure 1), measured by protection from surface sterilization. At each sample point, five similar leaves were pooled and processed as described in Materials and Methods. whereas at $30^{\circ} \mathrm{C}$ and above the hydathode selectivity was lost, i.e., $X c c$ was found distributed throughout the leaf.

\section{Comparison of A. thaliana accessions for ability to support entry of Xcc.}

The entry of wild-type $X c c$ into detached leaves of $41 \mathrm{~A}$. thaliana accessions was compared. For each accession, five leaves were used from each of two plants. The accessions grew at different rates, but as far as possible leaves of comparable age and size were used. After exposure to bacteria for 2 $\mathrm{h}$ and surface sterilization, the periphery of each leaf was dissected and both the periphery and the remainder of the leaf tissue were assayed for bacterial content. The accessions could be placed into three classes (Table 1). The majority, including the standard Col- 0 accession, fell in class A in terms of both total numbers and peripheral localization of bacteria. Class B accessions also showed peripheral localization, but the number of bacteria recovered was less than $5 \%$ of that in the class $\mathrm{A}$ accessions. In the class $\mathrm{C}$ accessions the bacteria were not preferentially localized at the periphery of the leaf: the relative CFU recovered from the periphery and the bulk tissue was in proportion to the relative area of leaf in the two fractions. The experiments were repeated so that each accession was studied three times, and although absolute numbers of bacteria recovered varied between experiments the trends were preserved. When representative accessions from each class were inoculated by syringe infiltration into leaf panels, all gave similar symptoms (Parker et al. 1993).

\section{Ability of Xcc mutants to enter leaves.}

The ability to enter leaves of some previously characterized $X c c$ mutants, which are altered in pathogenicity, was examined (Table 2). An hrp deletion mutant, which fails to show disease symptoms or to provoke a hypersensitive response, entered leaves at levels similar to that of the wild type, whereas $r p f B$, $r p f C$, and $r p f F$ regulatory mutants (which show reduced extracellular enzyme and polysaccharide synthesis) were less effective. The $r f a X$ mutant, which has defects in lipopolysaccharide synthesis, was severely impaired. Indeed, in most experiments no viable $r f a X$ bacteria could be recovered from leaves.

\section{Expression of the $X c c$ superoxide dismutase gene in bacteria within hydathodes.}

The production of active oxygen species follows infection of plants by bacteria. It is likely that this imposes a stress on the bacteria that is alleviated by protective enzymes, including superoxide dismutase, which is induced after infiltration of Xcc into Brassica spp. leaves (Smith et al. 1996). A. thaliana leaves were dipped into a suspension of wild-type Xcc harboring the plasmid pIJ3099, which carries the GUS coding region under the control of the Xcc sodA promoter (Smith et al. 1996). Viable counting showed that the entry of bacteria into the leaves was not affected by the plasmid. Histochemical analysis showed that although GUS activity was undetectable in the bacteria immediately after leaf dipping, the gene was strongly induced in the hydathode region by $4 \mathrm{~h}$ after exposure of leaves to bacteria (Fig. 3D). Subsequent experiments showed that GUS activity was detectable after $1 \mathrm{~h}$. Twentyfour hours after exposure the staining was more diffuse, suggesting that the bacteria had begun to migrate from the hydathodes (Fig. 3F). 


\section{DISCUSSION}

Although adaptation of bacteria to epiphytic colonization has been studied (Lindow 1996), processes involved in the transition between the epiphytic and parasitic phases have received little attention, probably because it is assumed that the ability of bacteria to penetrate natural openings or wounds is a passive process of limited interest to the molecular pathologist.

The experiments described in this paper were intended to establish a system for genetic study of hydathode colonization
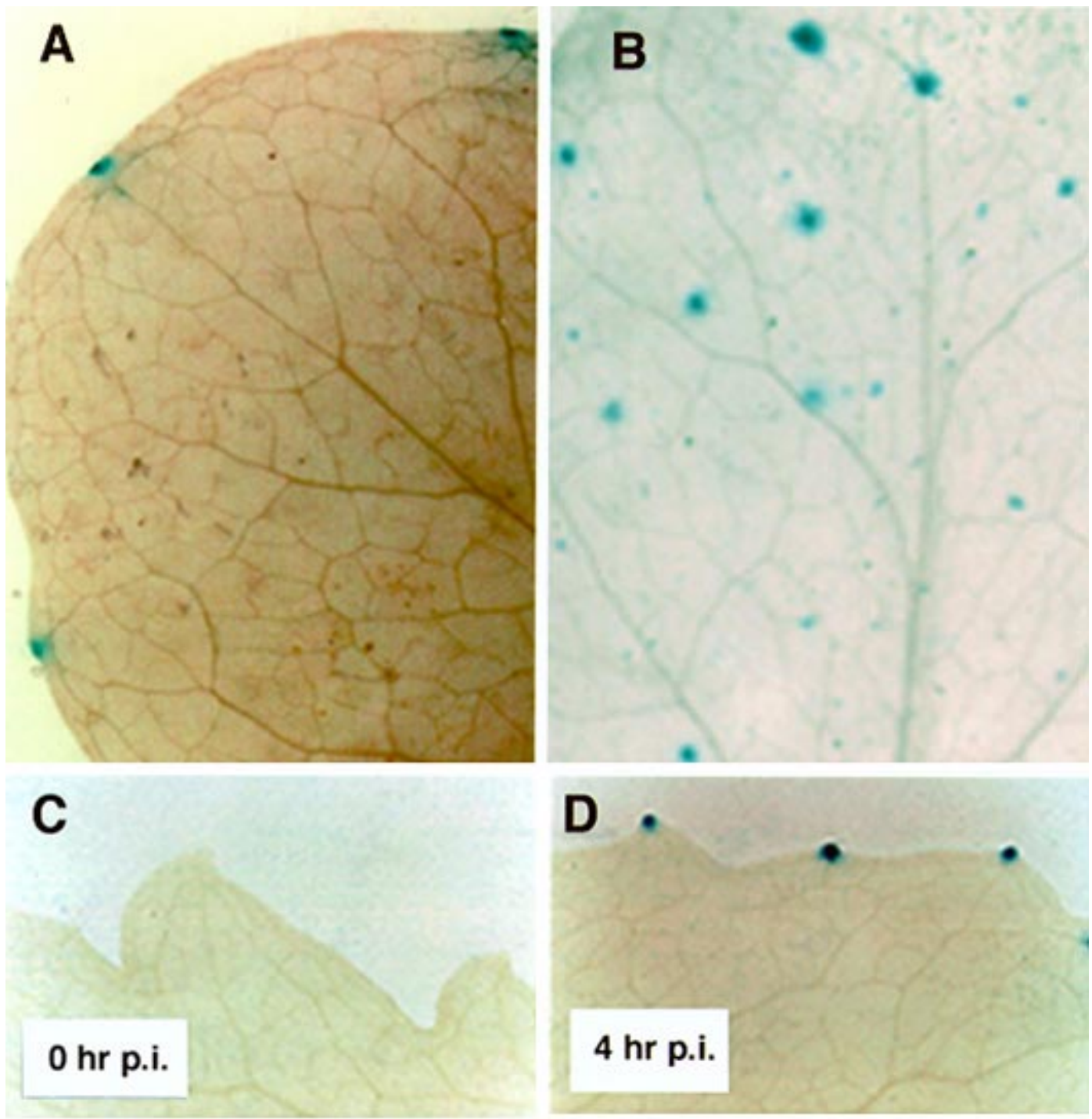

\section{$4 \mathrm{hr}$ p.i.}
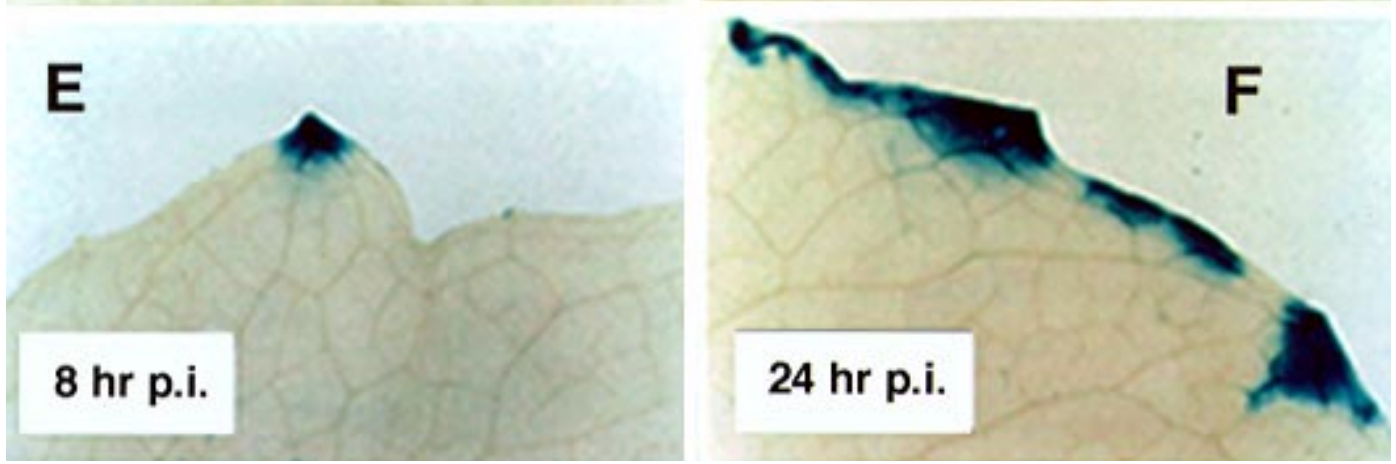

Fig. 3. Histochemical localization of $\beta$-glucuronidase produced by bacteria in leaves. A, Xanthomonas campestris pv. campestris (Xcc) or (B) X. campestris pv. armoraciae, each containing pL3GUS-A, was used in standard 2-h leaf dipping experiments. After being washed and surface sterilized, the leaves were incubated for a further $6 \mathrm{~h}$ to allow gene expression, and treated with substrate as described in Materials and Methods. Staining is confined to the hydathodes in $\mathbf{A}$, but is distributed in patches over the leaf area in $\mathbf{B}$. $\mathbf{C}-\mathbf{F}$, The time course and localization of $\beta$-glucuronidase accumulation driven by the sodA promoter in Xcc. Leaves were dipped in the bacterial suspension for 0, 4, 8, or $24 \mathrm{~h}$ before being processed as above (hr p.i. indicates hours after commencement of the inoculation dip). 
by $X c c$ that would enable both bacterial and plant attributes to be examined. A. thaliana is known to be a host for Xcc, but most of the previous work (including our work, described by Parker et al. 1993) has employed inoculation methods that bypass the hydathode and moreover introduce the bacteria into leaf panels rather than into their natural environment, the vascular system. We found that Xcc rapidly entered hydathodes of A. thaliana when intact, unwounded leaves were partially immersed in a bacterial suspension. The assay for entry was based on the resistance of internalized bacteria to surface sterilization of the leaf with sodium hypochlorite. Dissection of the sterilized leaf and histochemical localization of intracellular GUS showed that $X c c$ was localized in the hydathodes. Since the expression from pL3GUS-A is constitutive (Soby and Daniels 1996), the enzyme activity also serves as an approximate indicator of bacterial biomass. When similar experiments were performed with the leaf-spotting pathogen $X$. campestris pv. armoraciae, the enzyme activity was, in contrast, dispersed over the leaf panel in patches, reflecting stomatal entry into intercellular spaces of the leaf. Furthermore, the viable bacteria in this case showed no preferential concentration in the dissected edge of the leaf. Thus, our model system exhibits the correct portal of entry specificity for these two pathogens.

The increase in the number of protected bacteria observed over the first $6 \mathrm{~h}$ of leaf dipping probably reflects entry into hydathodes, whereas growth within the plant tissue probably contributes to the much larger number noted after $24 \mathrm{~h}$. Xcc is capable of growth within intercellular spaces of A. thaliana leaves, with a doubling line of approximately $8 \mathrm{~h}$ (Parker et al. 1993). Zoller (1972) showed that guttation fluid collected from cabbage hydathodes supported growth of Xcc, suggesting that the hydathode cavity is also likely to be an environment suitable for growth. The more diffuse GUS staining seen around hydathodes after $24 \mathrm{~h}$ (Fig. 3F) suggested that by this time bacteria were beginning to migrate from the hydathode into adjacent tissues. The disease symptoms that developed subsequently engulfed at least one-third of the leaf area, indicating spread from the hydathodes.

Leaf dipping experiments with $X c c$ harvested from early stationary phase cultures gave significantly larger numbers resistant to sterilization, compared with exponential phase

Table 1. Classification of Arabidopsis thaliana accessions according to behavior in the leaf dipping procedure ${ }^{\mathrm{a}}$

\begin{tabular}{|c|c|}
\hline Class & Accessions \\
\hline A & $\begin{array}{l}\text { Col-0, Mh-0, Kn-0, Ra-0, Co-1, Bd-0, Dijon G, Bay-0, Ws-0, } \\
\text { Bs-1, Lc-0, Bu-0, Je-54, Es-0, Gr-1, Dra-0, Pr-0, Cvi-0, S96, } \\
\text { RLD-1, Ag-0, Aa-0, Condora, Ang-0, Kas-1 }\end{array}$ \\
\hline B & $\begin{array}{l}\text { La-er, Bla-1, Cnt-1, Ost-0, Sorbo, H55, Mt-0, Ms-0, Tsu-1, Ct- } \\
\text { 1, Nd-0, Ita-1 }\end{array}$ \\
\hline $\mathrm{C}$ & Oy-0, Ler-1 \\
\hline \multicolumn{2}{|c|}{$\begin{array}{l}{ }^{a} \text { Class A: Accessions in which wild-type Xanthomonas campestris pv } \\
\text { campestris entered leaves in numbers comparable to those observec } \\
\text { under standard conditions with Col- } 0( \pm 50 \%) \text {, and in which }>80 \% \text { of } \\
\text { the total bacteria were localized in the peripheral region of the leaves } \\
\text { Class B: Bacteria were also localized in the periphery, but the tota } \\
\text { number was }<5 \% \text { of that observed with Col- } 0 \text {. Class C: Total numbers } \\
\text { were comparable to those with Col- } 0 \text {, but there was no preferentia } \\
\text { localization in the leaf periphery. Assignment was based on a series of } \\
\text { experiments in which each accession was tested with three leaves from } \\
\text { each of two plants, on three separate occasions. }\end{array}$} \\
\hline
\end{tabular}

cultures. It is not known whether stationary phase bacteria are more effective at entering hydathodes or whether they exhibit enhanced survival or growth within the hydathode. There is increasing evidence that known pathogenicity factors in Xcc (and other bacteria) are produced after the end of exponential growth (Arlat et al. 1991; Barber et al. 1997), and the present results may be related to this phenomenon.

The large collections of wild-type A. thaliana accessions constitute a valuable resource for detecting natural genetic variation in factors affecting host-pathogen interaction (Kunkel 1996). Our survey of a representative set of accessions suggested that three classes of behavior in the Xcc infection assay could be distinguished. Most accessions behaved like Col-O (class A). Class C supported substantially lower infection levels, but the bacteria were also localized primarily in hydathodes. However, the hydathode selectivity appeared to be absent for class B accessions. It will be informative to examine the genetic and physiological basis of the selectivity. Buell and Somerville (1997) mapped three genes in A. thaliana that confer resistance to an isolate of $X c c$, inoculated into leaf panels and therefore bypassing the hydathode. These genes were identified in crosses between accessions Col-0 and La-er, which fall in classes A and $\mathrm{B}$, respectively. It will be interesting to investigate whether the genes have the effect of restricting bacterial colonization of hydathodes. We anticipate that our procedure will be useful for future genetic studies of this kind.

Several classes of $X c c$ genes that affect pathogenicity have been discovered with plant inoculation tests that bypass hydathode entry. hrp mutants of Xcc, like similar mutants in other species, show reduced pathogenicity in compatible interactions and inability to provoke a hypersensitive reaction in incompatible interactions (Arlat et al. 1991). However, the Xcc hrp mutant used in these studies, which carries a deletion of approximately $20 \mathrm{~kb}$, removing essentially all the hrp gene cluster (Liddle 1992), was unaffected in hydathode colonization, indicating that entry into plants can be dissociated from other pathogenicity attributes. On the other hand, the rpf mutants tested showed reduced entry ability. These mutants are characterized by down-regulation of synthesis of extracellular enzymes and polysaccharide (Dow and Daniels 1994). Our results suggest that either these factors, or other, so far undiscovered, members of the $r p f$ regulons contribute to bacterial entry. It is noteworthy that the factors controlled by the rpf genes are synthesized in Xcc cultures only at the end of experimental growth (Barber et al. 1997), and bacteria harvested

Table 2. Ability of Xanthomonas campestris pv. campestris (Xcc) mutants to enter hydathodes ${ }^{\mathrm{a}}$

\begin{tabular}{llc}
\hline Strain & Genotype & Relative number of bacteria entering leaves \\
\hline 8004 & (wild type) & 1 \\
8420 & $\Delta h r p$ & 0.95 to 1.2 \\
8547 & $r p f A$ & 0.3 to 0.35 \\
8550 & $r p f B$ & 0.15 to 0.25 \\
8473 & $r p f C$ & 0.2 to 0.7 \\
8523 & $r p f F$ & 0.2 to 0.5 \\
8530 & $r f a X$ & 0 to 0.05 \\
\hline
\end{tabular}

${ }^{a}$ Standard 2-h leaf dipping experiments were performed with the indicated mutants and the wild-type $X c c$. Each mutant was tested on at least three occasions. Table gives range of numbers of bacteria that entered relative to numbers of the wild type in each experiment. 
at this point were also more effective at colonizing hydathodes. The most striking difference in hydathode colonization was seen with the $r f a X$ mutant, which is defective in lipopolysaccharide synthesis (Dow et al. 1995). The number of $r f a X$ bacteria entering hydathodes was much reduced, indeed in most experiments no viable cells could be recovered, even 24 to $48 \mathrm{~h}$ after inoculation. The mutant is known to be more sensitive than the wild type to certain antimicrobial compounds, such as novobiocin, plumbagin, and carbonyl cyanide 4-(trifluoromethoxy)-phenylhydrazone (Dow et al. 1995), probably because the lipopolysaccharide defect compromises ability to exclude certain compounds. However, the mutant is not more sensitive to paraquat, hydrogen peroxide, Tween 20, and Nonidet NP40, and is indeed more resistant than the wild type to Triton X100.

A priori, it is likely that hydathode colonization in our procedure depends on bacterial motility and chemotaxis. The Xcc mutants used in this study all show unimpaired motility, and general chemotaxis on swarm plates is also indistinguishable from wild type (A. Alvarez-Morales and M. J. Daniels, unpublished work). Moreover, the strains are not more sensitive than the wild type to the killing effects of sodium hypochlorite, suggesting that the reduced recovery is not an artefact of the experimental procedure. We consider that the inability to recover $r f a X$ mutants from the hydathode is most likely to be due to killing in a hostile chemical environment in the hydathode, perhaps created by a defense reaction. When inoculated into Brassica spp. leaf panels, $r f a X$ mutants show some reduction in numbers of viable bacteria for $24 \mathrm{~h}$, but the survivors then begin to grow at the same rate as wild-type bacteria (Dow et al. 1995). The existence of a hydathode-based defense reaction is supported by the rapid induction of the $\operatorname{sodA}$ (superoxide dismutase) gene in bacteria in hydathodes, inferred from increases in production of GUS driven by the sodA promoter (Fig. 3C-F). The gene is also induced, but more slowly, when bacteria are infiltrated into Brassica spp. or Capsicum spp. leaf panels. The sodA gene of Xcc is not induced by exogenous hydrogen peroxide or superoxide but is strongly induced by redox cycling agents such as plumbagin, a quinone of plant origin (Smith et al. 1996). The $r f a X$ mutant is also more sensitive to such agents (Dow et al. 1995). It is therefore possible that hydathodes contain such substances as an early line of defense. Certain genes whose products may have a role in defense have also been shown to be induced in hydathodes (Samac and Shah 1991).

Our purpose in carrying out these experiments was to develop a system that could be used to study natural bacterial entry. It should be possible to use the procedure to dissect the molecular details of the processes from both the bacterial and the plant perspective. For example, it is feasible, although laborious, to screen directly for mutants, either of $X c c$ or $A$. thaliana, showing altered entry behavior. Data from such studies may enhance the usefulness of hydathode-based resistance in plant breeding.

\section{MATERIALS AND METHODS}

\section{Bacterial strains and culture procedures.}

Xanthomonas campestris strains were grown with shaking at $32^{\circ} \mathrm{C}$ in NYGB broth as described by Turner et al. (1984). The following $X$. campestris pv. campestris strains were used:
8004 (wild type; Turner et al. 1984) and mutant derivatives of 8004: 8420 ( $h r p$ deletion mutant; Liddle 1992; Newman et al. 1994), 8547 (rpfA; Barber et al. 1996), 8550 ( $r p f B$; Barber et al. 1997), 8473 (rpfC; Tang et al. 1991), 8523 (rpfF; Barber et al. 1997), 8530 (rfaX; Dow et al. 1995). The X. campestris pv. armoraciae strain used was NCPPB 1930 from the National Collection of Plant Pathogenic Bacteria, Harpenden, UK. When bacteria were used for histochemical staining of GUS, plasmids carrying the gusA gene driven by the Escherichia coli lac promoter (p3GUS-A; Soby and Daniels 1996) or the Xcc sodA promoter (pIJ3099; Smith et al. 1996) were introduced into the strains by conjugation (Turner et al. 1984).

\section{Plant accessions and growth conditions.}

A. thaliana accessions listed in Table 1 were from the Sainsbury Laboratory collection (Parker et al. 1993) or from the Nottingham Arabidopsis Stock Centre (University of Nottingham, UK). Plants were grown as described by Parker et al. (1993) in a growth cabinet at $22^{\circ} \mathrm{C}$ with illumination for $8 \mathrm{~h}$ per day and were generally used 5 to 6 weeks after sowing. Unless otherwise specified the Columbia accession Col-0 was used.

\section{Procedure for studying hydathode colonization.}

Bacteria were harvested from broth cultures by centrifugation $(10,000 \times g, 10 \mathrm{~min})$, washed once, and suspended at $10^{8}$ $\mathrm{CFU} \cdot \mathrm{ml}^{-1}$ in sterile water containing Tween $80(0.02 \% \mathrm{vol} /$ vol). Thereafter, one of two procedures was used (Fig. 1), with either attached or detached leaves. For the former, selected leaves were carefully rolled about the midrib and 2-ml plastic microcentrifuge tubes were placed over the leaves. Great care was taken to avoid wounding the leaves. If necessary, the weight of the tubes was supported by adhesive tape affixed to a convenient support. Portions of the bacterial suspension were pipetted into the tubes so that about half the leaf area was immersed. The plant was kept at 22 to $25^{\circ} \mathrm{C}$ for the desired time of bacterial entry. Alternatively, leaves were detached from the plant and inserted into bacterial suspensions contained in wells of "Replidishes" (Sterilin, Teddington, UK) so that about half the leaf area was covered. Care was taken to ensure that the cut petioles were well clear of the suspension. Dishes were incubated at 22 to $25^{\circ} \mathrm{C}$. To determine the number of bacteria that had entered the leaves, the tissue was rinsed once with sterile water, then immersed for $1 \mathrm{~min}$ in a solution of commercial sodium hypochlorite bleach $(10 \%$ $\mathrm{vol} / \mathrm{vol})$ and Tween $80(0.02 \% \mathrm{vol} / \mathrm{vol})$, and finally washed three times with sterile water. The surface-sterilized leaves were then homogenized with a sterile mortar and pestle, the homogenates were serially diluted in water, and portions were plated on NYG agar containing rifampicin $\left(50 \mu \mathrm{g} \cdot \mathrm{ml}^{-1}\right)$ (Daniels et al. 1984) for determination of viable count. In some experiments with attached leaves, the rinsing and surface sterilization steps were carried out in situ and the plants were returned to the growth chamber to allow disease symptoms to develop (Parker et al. 1993).

Selective accumulation of bacteria at leaf margins (including hydathodes) was assessed by first surface sterilizing the leaves as above and then carefully excising peripheral strips approximately 0.5 to $1 \mathrm{~mm}$ wide with a sterile scalpel. The peripheral strips and the remainder of the leaf area were separately homogenized and the bacterial contents determined. 
Histochemical detection of GUS.

After being dipped in bacterial suspensions, washed, and surface sterilized, as described above, leaves were incubated at 22 to $25^{\circ} \mathrm{C}$ to allow bacterial gene expression to occur. They were then vacuum infiltrated with a substrate-detergent solution (5-bromo-4-chloro-3-indolyl $\beta$-D-glucuronide, $1 \mathrm{mg}$. $\mathrm{ml}^{-1}$, Triton X-100, 0.5\% vol/vol, polymyxin B, $0.2 \mathrm{mg} \cdot \mathrm{ml}^{-1}$, in $50 \mathrm{mM}$ sodium phosphate buffer $\mathrm{pH} 7.0$ ), incubated at $37^{\circ} \mathrm{C}$ overnight and fixed and decolorized in $80 \%$ ethanol at $70^{\circ} \mathrm{C}$.

\section{ACKNOWLEDGMENTS}

The Sainsbury Laboratory is supported by the Gatsby Charitable Foundation. V. H. was supported by the Human Capital and Mobility Scheme of the European Commission (contract CHRX CT 930170). The work was performed according to the terms of license PHF 1420B/1146/74 issued by the Ministry of Agriculture, Fisheries and Food under the Plant Health (Great Britain) Order 1993.

\section{LITERATURE CITED}

Arlat, M., Gough, C. L., Barber, C. E., Boucher, C., and Daniels, M. J. 1991. Xanthomonas campestris contains a cluster of hrp genes related to the larger hrp cluster of Pseudomonas solanacearum. Mol. PlantMicrobe Interact. 4:593-601.

Barber, C. E., Tang, J. L., Feng, J. X., Pan, M. Q., Wilson, T. J. G., Slater, H., Dow, J. M., Williams, P., and Daniels, M. J. 1997. A novel regulatory system required for pathogenicity of Xanthomonas campestris is mediated by a small diffusible signal molecule. Mol. Microbiol. 24:555-566.

Barber, C. E., Wilson, T. J. G., Slater, H., Dow, J. M., and Daniels, M. J. 1996. Some novel factors required for pathogenicity of Xanthomonas campestris pv. campestris. Pages 209-212 in: Biology of PlantMicrobe Interactions. G. Stacey, B. Mullin, and P. M. Gresshoff, eds. Proc. Int. Symp. Mol. Plant-Microbe Interact., 8th. IS-MPMI, St. Paul, MN.

Black, L. L., and Machmud, M. 1983. Xanthomonas leaf spot of crucifers. Page 126 in: Int. Congr. Plant Pathol., 4th.

Bretschneider, K. E., Gonella, M. G., and Robeson, D. J. 1989. A comparative light- and electron microscopical study of compatible and incompatible interactions between Xanthomonas campestris pv. campestris and cabbage (Brassica oleracea). Physiol. Mol. Plant Pathol. 34:285-297.

Buell, C. R., and Somerville, S. C. 1997. Use of Arabidopsis recombinant lines reveals a monogenic and a novel digenic resistance mechanism to Xanthomonas campestris pv campestris. Plant J. 12:21-29.

Cook, A. A., Walker, J. C., and Larson, R. H. 1952. Studies on the disease cycle of black rot of crucifers. Phytopathology 42:162-167.

Daniels, M. J., Barber, C. E., Turner, P. C., Cleary, W. G., and Sawczyc, M. K. 1984. Isolation of mutants of Xanthomonas campestris pv. campestris showing altered pathogenicity. J. Gen. Microbiol. 130: 2447-2455.

Dow, J. M., and Daniels, M. J. 1994. Pathogenicity determinants and global regulation of pathogenicity of Xanthomonas campestris pv. campestris. Pages 29-41 in: Current Topics in Microbiology and Immunology, Vol. 192: Bacterial Pathogenesis of Plants and Animals. J. L. Dangl, ed. Springer-Verlag, Berlin.

Dow, J. M., Osbourn, A. E., Wilson, T. J. G., and Daniels, M. J. 1995. A locus determining pathogenicity of Xanthomonas campestris is involved in lipopolysaccharide biosynthesis. Mol. Plant-Microbe Interact. 8:768-777.

Hunter, J. E., Dickson, M. H., and Ludwig, J. W. 1987. Source of resistance to black rot of cabbage expressed in seedlings and adult plants. Plant Dis. 71:263-266.
Kunkel, B. N. 1996. A useful weed put to work: Genetic analysis of disease resistance in Arabidopsis thaliana. Trends Genet. 12:63-69.

Liddle, S. A. 1992. Strategies for studying pathogenicity genes of Xanthomonas campestris pv. campestris. Ph.D. thesis. University of East Anglia, Norwich, UK.

Lindow, S. E. 1996. Molecular genetic approaches to assessing bacterial habitat composition, modification, and interactions on leaves. Pages 487-491 in: Biology of Plant-Microbe Interactions. G. Stacey, B. Mullin, and P. M. Gresshoff, eds. Proc. Int. Symp. Mol. Plant-Microbe Interact., 8th. IS-MPMI, St. Paul, MN

Lummerzheim, M., de Oliveira, D., Castresana, C., Miguens, F. C., Louzada, E., Roby, D., Van Montagu, M., and Timmerman, B. 1993. Identification of compatible and incompatible interactions between Arabidopsis thaliana and Xanthomonas campestris pv. campestris and characterization of the hypersensitive response. Mol. Plant-Microbe Interact. 6:532-544.

Newman, M.-A., Conrads-Strauch, J., Scofield, G., Daniels, M. J., and Dow, J. M. 1994. Defense-related gene induction in Brassica campestris in response to defined mutants of Xanthomonas campestris with altered pathogenicity. Mol. Plant-Microbe Interact. 7:553-563.

Onsando, J. M. 1992. Black rot of crucifers. Pages 243-252 in: Diseases of Vegetables and Oil Seed Crops (Vol. II) Plant Diseases of International Importance. H. S. Chaube, J. Kumar, A. N. Mukhopadhyay, and U. S. Singh, eds. Prentice Hall, Englewood Cliffs, NJ.

Parker, J. E., Barber, C. E., Fan, M.-J., and Daniels, M. J. 1993. Interaction of Xanthomonas campestris with Arabidopsis thaliana: Characterization of a gene from $X . c$. pv. raphani that confers avirulence to most A. thaliana accessions. Mol. Plant-Microbe Interact. 6:216-224.

Samac, D. A., and Shah, D. M. 1991. Developmental and pathogeninduced activation of the Arabidopsis acidic chitinase promoter. Plant Cell 3:1063-1072.

Shaw, J. J., and Kado, C. I. 1988. Whole plant wound inoculation for consistent reproduction of black rot of crucifers. Phytopathology 78: 981-986.

Simpson, R. B., and Johnson, L. J. 1990. Arabidopsis thaliana as a host for Xanthomonas campestris pv. campestris. Mol. Plant-Microbe Interact. 3:233-237.

Smith, E. F. 1897. A bacterial disease of cruciferous plants. Science N.Y. 5:963.

Smith, S. A., Wilson, T. J. G., Dow, J. M., and Daniels, M. J. 1996. A gene for superoxide dismutase from Xanthomonas campestris pv. campestris and its expression during bacterial-plant interactions. Mol. Plant-Microbe Interact. 9:584-593.

Soby, S. D., and Daniels, M. J. 1996. Catabolite-repressor-like protein regulates the expression of a gene under the control of the Escherichia coli lac promoter in the plant pathogen Xanthomonas campestris pv. campestris. Appl. Microbiol. Biotechnol. 46:559-561.

Staub, T., and Williams, P. H. 1972. Factors influencing black rot lesion development in resistant and susceptible cabbage. Phytopathology 62: 722-728.

Sutton, J. C., and Williams, P. H. 1970. Relation of xylem plugging to black rot lesion development in cabbage. Can. J. Bot. 48:391-401.

Tang, J. L., Liu, Y.-N., Barber, C. E., Dow, J. M., Wootton, J. C., and Daniels, M. J. 1991. Genetic and molecular analysis of a cluster of $r p f$ genes involved in positive regulation of synthesis of extracellular enzymes and polysaccharide in Xanthomonas campestris pathovar campestris. Mol. Gen. Genet. 226:409-417.

Tsuji, J., Somerville, S. C., and Hammerschmidt, R. 1991. Identification of a gene in Arabidopsis thaliana that confers resistance to Xanthomonas campestris pv. campestris. Physiol. Mol. Plant Pathol. 38:57-65.

Turner, P., Barber, C., and Daniels, M. 1984. Behaviour of the transposons Tn5 and Tn7 in Xanthomonas campestris pv. campestris. Mol. Gen. Genet. 195:101-107.

Wallis, F. M., Rijkenberg, F. H. J., Joubert, J. J., and Martin, M. M. 1973. Ultrastructural histopathology of cabbage leaves infected with Xanthomonas campestris. Physiol. Plant Pathol. 3:371-378.

Zoller, B. G. 1972. Growth and movement of Xanthomonas campestris in natural fluids of cabbage. Ph.D. thesis. University of California, Davis. 